\title{
An Innovative Teaching Method and Its Practical Applicability - Focus on the Playful Interaction Among the Students
}

\author{
Enikő KORCSMÁROS*, Renáta MACHOVÁ, Lilla FEHÉR and Zsuzsanna TÓTH \\ J. Selye University, Komárno, Slovakia, korcsmarose@ujs.sk; machovar@ujs.sk; feherl@ujs.sk; tothz@ujs.sk \\ * Corresponding author: korcsmarose@ujs.sk
}

\begin{abstract}
The research related to innovation has been in a focus of academics for a long time. In the current study, the authors present the positive benefits of applying an innovative teaching method, based on primary research, applying a questionnaire-based survey. The innovative teaching methods may significantly change the traditional lessons. The questionnaire was completed anonymously in October 2019 and February 2020. Evaluated sampling as a form of non-random sampling was applied. There were 236 questionnaires evaluated after the application of the simulation software. We used SPSS to analyze the obtained data. The defined research question was: Is it possible to form different groups based on playful interaction among students? The Ward-method, as a hierarchical method was used for cluster analysis. We finally decided on two-cluster solution: cluster 1 called as a cluster of playful learning students and cluster 2 as a cluster of "uninterested negatives". Novel methods in education play an essential role in the Slovak education system.
\end{abstract}

Keywords: innovation; playful learning; education; teaching method

JEL Classification: I21; I29; J24

\section{Introduction}

Currently we are being faced by constant change, which is accompanied with innovation in different fields of our life. The term „,innovation“ is associated with the name of Schumpeter in historical context. He defined innovation as a process, which starts with a creative idea that can be implemented into practice. Since our research is focusing on innovation applied in education, we will introduce the theoretical background of the issue in this context. Our study will present the difference between the generations and their characteristics, as well as their position on the labour market. One of the biggest challenges of the corporate sector is the coordination of cooperation and working methods of these generations. The focus shifts on online activity of the younger generation and their commitment to IT tools. In contrast to emphasizing the negative impact of the above mentioned tools, the authors will introduce the positive, labour market enhancing use of innovative teaching methods. (Werbach \& Hunter, 2012)

Innovation is also present in the education, which contributes to efficiency of education, supports the teacher in work and enables them to apply different methods of knowledge transfer, as well as provides students with an opportunity to try new methods of acquiring 
knowledge. Since the students participating in education process are different, the use of different methods in the education process can lead to selection of the most effective methods to be applied in the education process (Szőköl, 2018; Zelenková \& Hanesová, 2019).

The specific professional knowledge that is associated with competitiveness is based on high level of general knowledge. The technological progress is accelerating, which makes it difficult to determine the future of professions. However, there are certain competencies and attitudes that can be attributed to certain profession. Different competencies can be assigned to different fields, but there are certain competencies e.g. problem-solving ability, motivation, creativity, which can be listed as universal competencies. (Makó, 2015)

The interactive education will enable the students to become equal participants in a research-based education, and thus to be involved in the process of discovery, innovation and learning from mistakes. One of the main benefits of this new approach is that they learn to think, act, and make decisions professionally, thus developing their professional identity. (Holmes, Wieman, \& Bonn, 2015)

These interactive techniques make the education process more attractive, authentic and satisfying - full of challenges that need to be addressed and lead to better education results. The active engagement can include several "provocations“, which are carefully planned by instructors, as well as will enable understanding and engagement in the educational process. Interactive teaching provides a possibility for the lecturer to persuade the students to participate in the process of online learning by using online materials, quizzes and other methods before entering the traditional classroom. Collecting data via responses can provide information for the lecturer, who can tailor the presentation and progress with the curriculum based on the collected data. The transition to active form of education leads to replacement of traditional didactics, where students will progress based on predetermined set of steps. The active methods of teaching are designed to help students solving problems while asking questions. As a result of this, the students will share their "experimental proposal“. It can be described that the previous traditional methods are like recipes used for cooking and baking. (Zelenková \& Hanesová, 2019) In contrast, innovative teaching methods are more authentic, require teamwork and higher level of awareness. Students can be prepared not only for specific "textbook" problems, but also for situations where the answer is not known in advance. This approach makes students to recognize that conclusions can rarely be recognized final, they need to be modified and finalized. (Zichermann \& Linder, 2013) Active education requires a high level of interaction between the students and the teacher, as well as the student and the curriculum. The strategy of education should include the following aspects:

- Guided preparation for lessons - students should be prepared for interactions that might occur on the lessons. Therefore, not only the teachers, but also the students have to prepare for the lecture. It will increase the quality and frequency of the interactions.

- Time for reflection - following the interactions, students should be given a time for thinking and discussion in order to place the acquired learning material into further context.

- Applying mixed teaching techniques - the teacher should not insist on a specific technique, but use different techniques in different combinations and alternately. 
- Increased emphasis on applying knowledge - interactions put increased emphasis on the application of new and existing concepts and knowledge in new and existing contexts.

- The „importance“ of incorrect answer - accepting that the „incorrect" answer is also a necessary and positive step towards the sustainable education.

- The need for different measurement methods - help students to realize what they already know and what they are capable of. (Talbota et al., 2016)

The nature of innovative education offers more opportunities to correct misconceptions, to provide feedback in time, and integration of perspectives through discussions and discovery. As responsibility shifts towards the student, these methods are able to adapt to the educational abilities of the individuals, different professional directions and diversity of student aspirations (Deslauriers, Schelew, \& Wieman, 2011; Freeman et al., 2014; Rózsa, 2018).

According to the following scheme below, we can assume that each individual expression is interpreted in two dimensions. One of the dimensions focuses on distinction between the concept of play (n) and play (v). Deterding (2011) explains the difference between them clearly. While the game is played, it can also have a broader meaning. As for the definition of "game", he can agree with the classical definitions of the term, according to which individuals are trying to achieve a certain goal or results during the game, while the whole process is characterized by rules, competition and possible disputes as well.

The second dimension differentiates the "serious game ", and "gamification" on the basis of the elements of the game and based on the game as an entire activity. As it was earlier mentioned in the text, we use game elements in a playful environment also during gamification, but the limits of applying game elements are unclear, so it is often difficult to distinguish serious game from gamification. (Deterding et al., 2011; Blštáková, Piwowar-Sulej, 2019)

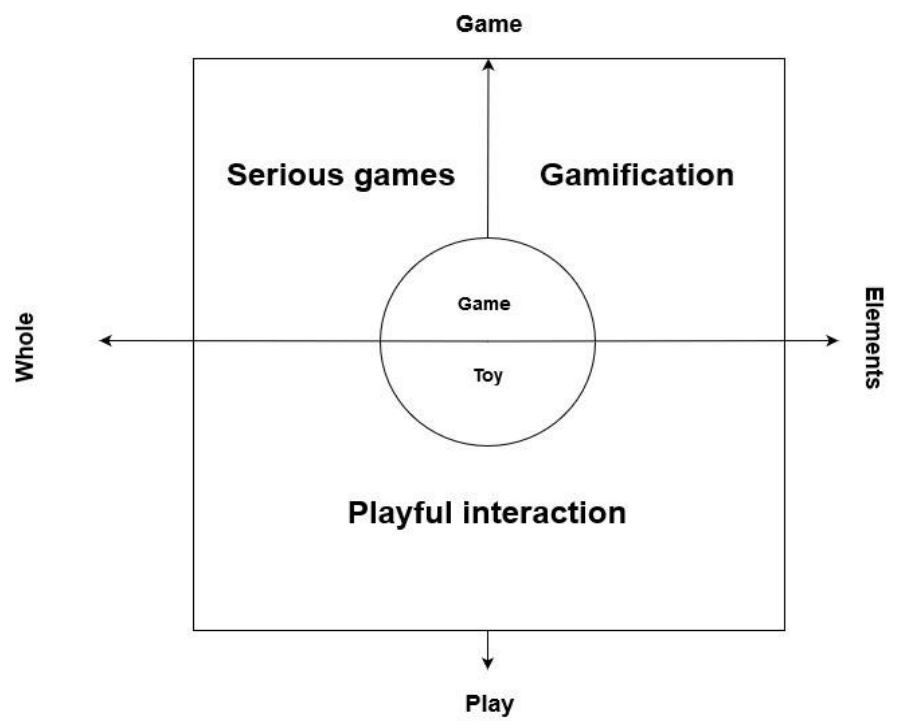

Figure 1. Difference between game, serious game and gamifcation (Deterding et al., 2011, p. 2)

\section{Methodology}

The aim of the research is to map the experience related to practical use of the simulation software as an innovative teaching method. To achieve our goal, we conducted a 
primary research in form of a questionnaire survey. The questionnaire was completed anonymously in October 2019 and February 2020. Evaluating sampling as a form of non-random sampling was applied, the selection of elements is based on the researcher's decision. There were collected 236 questionnaires after the application of the software. We used SPSS to analyze the obtained data.

In order to achieve the research goals, the research questions were outlined:

Is it possible to form different groups based on playful interaction among the students? In addition to univariate analyzes, e.g. mean, mode, standard deviation, which provide an insight into the opinion of the respondents, we also applied multivariate analysis for deeper analysis of the obtained data. In this research the cluster analysis will be highlighted. The main objective was to obtain detailed information about the individuals forming certain groups. The Ward-method, as a hierarchical method was used for cluster analysis.

$$
d_{\text {Ward }}\left(C_{i}, C_{j}\right)=\sum_{u, v \in C_{i} \cup C_{j}} d^{2}(u, v)-\left(\sum_{u, v \in C_{i}} d^{2}(u, v)+\sum_{u, v \in C_{j}} d^{2}(u, v)\right)
$$

Using the Ward's method, we can minimize the squares within the clusters, and merge the two clusters that cause the lowest square error increase (Fogaras \& Lukács, 2005). Within the clusters we conducted the cluster table analysis related to gender, place of residence and generation group of the respondents. The further relationship between the factors was examined using a Chi-Square test and Cramer V.

The research question focused on creating different groups of students based on the assessment of playful learning. In order to answer the question, a cluster analysis was used in the SPSS system. The aim of the method is to arrange the observation units into a homogeneous group based on the variables involved in the analysis. The cluster analysis is successful if the individuals forming a group share similarities, but relevant deviation can be detected among the different groups. The cluster analysis is trying to create groups of observed individuals. The process of cluster analysis was started by defining the problem and formulating the research question. The last question of the questionnaire was relevant following the application of the software, as we wanted to organize our students into groups based on these 14 statements. Before running the cluster analysis, it is necessary to examine the conditions of the analysis. There was no need to standardize the data, as our variables were measured on a five-point metric scale, and no flagrant elements were detected. The correlation between the variables was not too high either, so clustering was made possible. Since our variables are measured on a metric scale, two observation units can be considered similar, when the distance between them is small, and they are the same if the distance between them equals to zero. The Euclidean distance was used to measure the distance. The next step of the cluster analysis is to select the cluster method to be applied. There are two methods of clustering. We can differentiate the hierarchical and non-hierarchical cluster formation. Decision about which method is more appropriate is not an easy task. According to professional recommendation, it is advisable to use the methods together. The ideal number of clusters was determined by using the Ward-technique as a hierarchical method. 


\section{Results}

To determine the number of clusters, we examined the aggregation algorithm and the dendogram, based on which both the two- and three-cluster solutions required further examination. The following step of the examination was the interpretation and characterization of the clusters, which can be conducted based on the cluster centroids (average). The first analysis included only those factors that contributed to forming the clusters, and later the characterization of each group was performed with the help of variables not included in the clusterization. To make decision about the number of clusters, we also examined the standard deviation of the clusters, which contributed to deduction of homogeneity. The three-cluster and two-cluster solutions resulted in groups of almost the same homogeneity, but in the case of the two-cluster solution the standard deviation of our first cluster improved, so finally decided on two-cluster solution. $66 \%$ of the students were classified to Cluster 1, while 34\% were classified to Cluster 2 . The clusters were named and characterized based on the answers of respondents provided for statements about playful learning.

Table 1. Cluster 1

\begin{tabular}{|l|l|c|}
\hline & Cluster 1 & Average \\
\hline I enjoy competition. & 3.60 & 3.86 \\
\hline New tasks are equal to new challenges, which are inspiring. & 3.31 & 3.60 \\
\hline Integrated usage of knowledge. & 3.31 & 3.66 \\
\hline I get to know new skills about myself. & 3.18 & 3.51 \\
\hline Reward after solving a certain amount of tasks. & 3.15 & 3.51 \\
\hline I solve more and more difficult tasks. & 3.13 & 3.42 \\
\hline Tasks to be solved evoke unexpected positive emotions. & 3.10 & 3.37 \\
\hline I can try and prove my desires. & 3.03 & 3.46 \\
\hline The new tasks generate desire. & 2.92 & 3.31 \\
\hline As the best part, I can try and fulfill different roles. & 2.90 & 3.24 \\
\hline The roles helped me re-evaluate my out-of-game options. & 2.90 & 3.36 \\
\hline I can get easily angry if cannot solve a task. & 2.82 & 2.71 \\
\hline After completing a task, the reward is a new task. & 2.46 & 2.85 \\
\hline Tasks to be solved trigger unexpected negative feelings. & 2.08 & 2.17 \\
\hline
\end{tabular}

The first cluster is formed by 156 students, who do not really enjoy the opportunity of competition provided by game. Regarding the brief demographic characteristics of the representatives of the first cluster, we consider it important to indicate that from an age point of view, the cluster is represented in most of the representative of generation $\mathrm{Y}$. Although members of generation $\mathrm{Y}$ are characterized by the fact that technology makes their everyday lives easier, the use of simulation software has not won their favor. The reward is not really motivating for them, and they get angry easily, when they cannot solve the task. There negative and positive emotions during the game are not outrageous either. Based on the values presented in the table above, this group enjoyed the application of simulation 
software less, the game rather brought negative attitudes to the surface, so this group is called the "uninterested negatives". The teacher has a key role to play raising the students' awareness on playful learning, motivating them to compete, and applying tools to raise interest of the students in playful learning.

Table 2. Cluster 2

\begin{tabular}{|l|c|c|}
\hline & Cluster 2 & Average \\
\hline I enjoy competition. & 4.40 & 3.86 \\
\hline Integrated usage of knowledge. & 4.35 & 3.66 \\
\hline I can try and prove my desires. & 4.30 & 3.46 \\
\hline The roles helped re-evaluate my out-of-game opportunities. & 4.25 & 3.36 \\
\hline Reward after solving certain amount of tasks. & 4.20 & 3.51 \\
\hline New tasks are equal to new challenges, which is inspiring. & 4.15 & 3.60 \\
\hline I get to know new skills about myself. & 4.15 & 3.51 \\
\hline The new tasks generate desire. & 4.05 & 3.31 \\
\hline I solve more and more difficult tasks. & 4.00 & 3.42 \\
\hline The tasks to be solved evoke unexpected positive emotions. & 3.90 & 3.37 \\
\hline As the best part, I can try and fulfill different roles. & 3.90 & 3.24 \\
\hline After completing a task, the reward is a new task. & 3.60 & 2.85 \\
\hline I can easily get angry if cannot solve the task. & 2.50 & 2.71 \\
\hline The tasks to be solved trigger unexpected negative feelings. & 2.35 & 2.17 \\
\hline
\end{tabular}

Cluster 2 is formed by a smaller group of students. The cluster is represented in most of the representative of generation $\mathrm{Z}$. Members of generation $\mathrm{Z}$ are already born into a world of digital technologies where it is unthinkable for them to live without the use of mobile phones, computers and other digital and communication devices. Members of generation $\mathrm{Z}$, as they grew up in a new world, have completely changed their learning habits. This also raises problems in the education system, especially in the area of teaching methods. It is difficult for teachers to pass on their knowledge to young people who are accustomed to the rapid flow of information and its reception. There are 80 students in the cluster, which forms $34 \%$ of the sample. They enjoy competition, the opportunity to integrate their knowledge gained by studying different subjects, and they want to prove their abilities. They will not get angry if cannot solve tasks as well as the tasks to be solved do not generate negative feelings. It is benefiting to focus the attention of students on competition, reward and new challenges. This cluster is formed by the "competing positives". Statistical testing of average differences is essential. An independent sample t-test was used for testing. After performing the independent sample t-test, we found that the opinion of our two clusters differs significantly for all statements.

\section{Discussion and Conclusions}

The aim of the research is to map the experience related to practical use of the simulation software as an innovative teaching method. In the following, we will provide the characterization of each cluster on the basis of three demographic variables (gender, place of 
residence, generational categorization) not included in clustering. Since all three of our demographic questions are not measured on a metric scale, nor clustering is measured on a metric scale, so we chose the cross-tab analysis. Considering the distribution by gender and the place of residence, both of our clusters are mainly formed by women and rural residents. It is not surprising since female respondents and respondents with the place of rural residence are over-represented in the sample. There is a significant $(\chi 2=0.008)$, but weak relationship (Cramer' $\mathrm{V}=0.171$ ) between the gender and the clustering factors. There is no significant relationship between the place of residence and clustering $\left(\left(\chi^{2}=0.066\right)\right.$. There is a weak $($ Cramer' $\mathrm{V}=0.131)$, significant $(\chi 2=0.044)$ relationship between the generation categorization and clustering. The group of "unintrested negatives" is formed by the representatives of Generation Y (54\%), while the group of "competitive positives" is formed by the representatives of Generation $Z(60 \%)$. The research results suggest that the novel method of playful learning can be adopted much faster by younger generation, so it is worth to introduce applications supporting playful learning and simulation softwares to younger generation.

The most important conclusions of our cluster analysis is that it is more difficult for the older generation respondents to open to technological challenges. They were more skeptical about application of the software in the education process, so the role of the teacher is to motivate them to accept the new methods of teaching. In contrast, the representatives of younger generation are open to new methods applied in the education process, it is worth to put emphasis on competition, which can be defined as a strong labour market competence. Based on the obtained research results, we can assume that the novel methods in education play an essential role in the Slovak education system, as they result in strengthening labour market competencies among the members of young generation.

Acknowledgments: The scientific article is a partial output from the KEGA project 005UJS-4/2019 entitled "Streamlining Managerial Sills of the generations $\mathrm{Z}$ and $\mathrm{Y}$ by gamification on the context of linking science and practice", which is solved at the Faculty of Economics and Informatics of the J. Selye University in Komárno.

\section{References}

Blštáková, J., \& Piwowar-Sulej, K. (2019). Gamification as an innovative idea within human resources management. In P. Jedlička, P. Marešová, \& I. Soukal (Eds.), Hradec Economic Days (Vol. 9, pp. 77-88). University of Hradec Králové. https://uni.uhk.cz/hed/site/assets/files/1073/proceedings_2019_1-1.pdf

Deslauriers, L., Schelew, E., \& Wieman, C. (2011). Improved Learning in a Large-Enrollment Physics Class. Science, 332(6031), 862-864. https://doi.org/10.1126/science.1201783

Deterding, S., Sicart, M., Nacke, L., O'Hara, K., \& Dixon, D. (2011). Gamification. Using game-design elements in non-gaming contexts. In Proceedings of the 2011 Annual Conference Extended Abstracts on Human Factors in Computing Systems - CHI EA '11, 2425. https://doi.org/10.1145/1979742.1979575

Fogaras, D., \& Lukács, A. (2005) Klaszterezés (Clustering). In Informatikai algoritmusok II. 29. Fejezet. (pp. 13951435). ELTE, Budapest. http://web.cs.elte.hu/ lukacs/Papers/klaszterezes.pdf

Freeman, S., Eddy, S. L., McDonough, M., Smith, M. K., Okoroafor, N., Jordt, H., \& Wenderoth, M. P. (2014). Active learning increases student performance in science, engineering, and mathematics. Proceedings of the National Academy of Sciences of the United States of America, 111(23), 8410-8415.

Holmes, N. G., Wieman, C. E., \& Bonn, D. A. (2015). Teaching critical thinking. Proceedings of the National Academy of Sciences of the United States of America, 112(36), 11199-11204. https://doi.org/10.1073/pnas.1505329112

Makó, Á. (2015). A szakképzett pályakezdők munkaerő-piaci helyzete és elhelyezkedési esélyei. Közgazdasági Szemle, 62(5), 502-524. 
Rózsa, Z. (2018). Ghostwriting among business management students. Acta Oeconomica Universitatis Selye, 7(2), 151-161.

Szőköl, I. (2018). Continuous Improvement of the Teaching Process in Primary Education. Journal of Language and Cultural Education, 6(1), 53-64. https://doi.org/10.2478/jolace-2018-0004

Talbot, R. M. I., Doughty, L., Nasim, A., Hartley, L., Le, P., Kramer, L. H., Kornreich-Leshem, H., \& Boyer, J. (2016). Theoretically Framing a Complex Phenomenon: Student Success in Large Enrollment Active Learning Courses. Physics Education, 344-347. https://doi.org/10.1119/perc.2016.pr.081

Werbach, K., \& Hunter, D. (2012) For the win: How Game Thinking Can Revolutionize Your Business. Wharton, Philadelphia.

Zelenková, A., \& Hanesová, D. (2019) Intercultural competence of university teachers: a challenge of internationalization. Journal of Language and Cultural Education, 7(1), 1-18, https://doi.org/10.2478/jolace-2019-0001

Zichermann, G., \& Linder, J. (2013). The Gamification Revolution: How Leaders Leverage Game Mechanics to Crush the Competition. McGraw-Hill. 